\section{Estudo \\ Ecidebate}

em Testão

Planejamento
Revista Estudo \& Debate, Lajeado, v. 26, n. 2, 2019. ISSN 1983-036X

DOI: http://dx.doi.org/10.22410/issn.1983-036X.v26i2a2019.1985

\title{
EXPRESSÃO TERRITORIAL DA RELAÇÃO GLOBAL-LOCAL: O MOVIMENTO NÓS PODEMOS EM SANTA CATARINA
}

\author{
Janaina Mayara Müller da Silva ${ }^{1}$, Oklinger Mantovaneli Junior ${ }^{2}$
}

\begin{abstract}
Resumo: Em meio a processos globais de desenvolvimento, tem-se salientado estudos que permitem identificar as influências globais no desenvolvimento regional. Com o objetivo de dar visibilidade a estas influências, este artigo apresenta a institucionalização do Movimento Nós Podemos em Santa Catarina, como mecanismo intensificador desta relação, ou mais especificamente, como a expressão territorial da relação global-local. Para isto, foi realizada pesquisa exploratória, descritiva e teórica-empírica, com base em um estudo de caso. Também adotou-se a pesquisa bibliográfica, documental e entrevistas semiestruturadas para compreender o processo de institucionalização do Movimento. Destaca-se que a atuaçáo do Movimento, por meio da territorialização de agendas globais para o desenvolvimento, como os 'Objetivos de Desenvolvimento do Milênio' e 'Objetivos de Desenvolvimento Sustentável', materializa e intensifica a relação global-local e contribui, portanto, para a padronização de estratégias de desenvolvimento regional.
\end{abstract}

Palavras-chave: Movimento Nós Podemos. Agendas Globais. Desenvolvimento Regional.

\section{TERRITORIAL EXPRESSION OF THE GLOBAL-LOCAL RELATIONSHIP: THE MOVEMENT WE CAN IN SANTA CATARINA}

\begin{abstract}
In the midst of global development processes, studies have been made to identify global influences on regional development. With the objective of give visibility to these influences, this article presents the institutionalizaion of the Movement We Can in Santa Catarina, as an intensifying mechanism of this relation, or more specifically, as the territorial expression of the global-local relationship. For this, an exploratory, descriptive and theoretical-empirical research was carried out, based on a case study. Bibliographical, documentary and semistructured interviews were also used to understand the process of institutionalization of the Movement. It is noteworthy that the Movement, through the territorialization of global agendas for development, such as the 'Development objectives of the Milênnim' and 'Development of sustainable Objectives', materializes
\end{abstract}

1 Doutoranda em Serviço Social pela Universidade Federal de Santa Catarina (UFSC). Mestre em Desenvolvimento Regional e bacharel em Serviço Social pela Universidade Regional de Blumenau (FURB). E-mail: janainamayms@gmail.com.

2 Pós-Doutor em Planejamento e Gestão do Território (UFABC). Doutor em Sociologia (UNESP). Mestre em Administração (UFSC). Pesquisador do CNPq. Professor do Programa de Pós-Graduação em Desenvolvimento Regional (FURB). Coordenador do Grupo de Pesquisa Núcleo de Políticas Públicas (NPP). E-mail: oklingerfurb@gmail.com. 
and intensifies the global-local relationship and contributes, therefore, to the standardization of strategies Development.

Keywords: Movement We Can. Global Agendas. Regional development.

\section{Introdução}

A globalização tem sido concebida como um processo de intensa troca entre países, permitindo a interação entre indivíduos e regióes em escala mundial. O termo é carregado de controvérsia teórica, apontando uma visão dualista: ora catastrófica e pessimista, ora cornocopiana e otimista. Isto significa que há teorias que indicam o processo como mecanismo fundamental para o desenvolvimento econômico mundial e evolução dos meios tecnológicos, mas também há a sua condenação, pelo aumento das desigualdades e descaracterização da identidade das naçóes. Entre dicotomias, pode se afirmar que o processo de globalização: a) permite a expansão e consolidação do sistema capitalista, ampliando alternativas neoliberais para o desenvolvimento; b) impóe e intensifica uma relação entre o global e o local; e c) embora seja um processo homogêneo, provoca transformaçóes distintas em cada região, considerando as especificidades das mesmas.

$\mathrm{Na}$ mesma direção, o desenvolvimento também se relaciona aos processos globais, o que pressupóe a transformação de padróes de desenvolvimento e de regióes, através de processos emergidos da globalização. Esta influência global no desenvolvimento pode ser constatada de diversas formas. A imposição das 'Estratégias Internacionais de Desenvolvimento' ${ }^{3}$ para nortear o desenvolvimento dos países, mediante a assimilação de agendas globais como os 'Objetivos de Desenvolvimento do Milênio (ODM)' e 'Objetivos de Desenvolvimento Sustentável (ODS)', é um exemplo disto. Estas agendas, embora globais, dispóem de objetivos, metas e indicadores que incidem em problemáticas inerentes ao desenvolvimento local, ou seja, subentende uma aplicabilidade local. Portanto, agendas globais com aplicabilidade local podem materializar e intensificar a relaçáo entre o global e o local, no que se refere a estratégias de desenvolvimento.Para dar visibilidade à relação entre o global e o local estimulada por estas agendas globais de desenvolvimento, este artigo apresenta o processo de territorialização das mesmas. Mais especificamente, busca-se demostrar a atuação do Movimento Nós Podemos na territorialização das agendas globais em todo o País, e, particularmente, no estado de Santa Catarina. A atuação do Movimento no território, por meio da territorialização de agendas globais, permite tanto materializar a relação global-local nas estratégias de desenvolvimento, quanto produzir um novo padrão de organização da sociedade civil, também em prol do desenvolvimento. Este processo de territorialização ocorre por meio da sensibilização da sociedade, para que instituições locais desenvolvam açóes nos territórios que permitam melhorar os indicadores locais de desenvolvimento, e consequentemente, nacionais. Até 2015, o Movimento sensibilizou cerca de 2000 organizaçóes, que assumiram o compromisso com a agenda ODM e desenvolveram atividades locais que contribuíram para o cumprimento dos objetivos globais. No Estado de

3 Estratégias elaboradas pela Organização das Naçóes Unidas (ONU), através do Programa das Naçóes Unidas para o desenvolvimento (PNUD). 
Santa Catarina, o Movimento foi instituído em 2009 e até 2015 mobilizou 184 instituições, distribuídas em 25 municípios.

Parte-se do pressuposto de que a expressão territorial do Movimento no Estado de Santa Catarina condiz com a materialização da relação global-local, pois o mesmo estimula que sejam adotadas estratégias globais em açóes locais para o desenvolvimento. Ou ainda, a materialização de um pacto global constitui o processo por meio do qual uma agenda global se difunde territorialmente, interferindo no desenvolvimento de uma regiâo. Isto pressupóe dois eixos analíticos: a) a relação entre globalização e território - o processo de globalização pode ser territorializado por meio da disseminação de agendas globais, ou mais especificamente, pela atuação do Movimento Nós Podemos - o que indica que nesta relação, o Movimento constitui uma expressão localizada de uma agenda global; b) a relação entre sociedade civil e desenvolvimento regional - a sociedade civil interfere no desenvolvimento de cada local - logo, nesta relação, o Movimento Nós Podemos constitui a expressão de como a organização social influencia o desenvolvimento regional.

Diante deste conjunto de questóes, foi realizada uma pesquisa exploratória, descritiva e teórica-empírica, com base em um estudo de caso - a institucionalização do Movimento em Santa Catarina ${ }^{4}$. Também foi necessário o desenvolvimento de pesquisa bibliográfica, documental e a realização de entrevistas semi-estruturadas ${ }^{5}$ para compreender o processo de institucionalização do Movimento no Estado. Para exposição, este artigo está dividido em cinco partes: 1) introdução; 2) processos globais e sua relação com o desenvolvimento regional; 3) sociedade civil e o território como fatores que interferem na construção do desenvolvimento; 4) parte empírica do trabalho - a institucionalização do Movimento Nós Podemos no Brasil e, mais especificamente, no Estado de Santa Catarina, enfatizando suas práticas socioespaciais na construção do desenvolvimento e; 5) considerações finais.

\section{Processos globais e desenvolvimento regional}

Para compreender a expressão territorial de uma relação que se estabelece entre o global e o local é necessário entender como o processo de globalizaçáo surge e qual o impacto disto na construção do desenvolvimento. Estas escalas, embora pareçam distintas, se relacionam por meio de estratégias de desenvolvimento que, mesmo constituídas a nível global, são implantadas e impactam em todas as escalas do desenvolvimento. Logo, há um processo de padronização das estratégias para tal, inclusive para resolução de possíveis 'problemáticas' do desenvolvimento. Neste sentido, o processo de globalização também está diretamente relacionado com o desenvolvimento regional, interferindo na construção e transformação de regióes e padronizando formas de desenvolvimento.

4 Optou-se pela delimitação do Estado de Santa Catarina devido à proximidade ao território analisado. Também se optou pela delimitação temporal, compreendendo o período de 2009 a 2015, por considerar o ano de criação do Movimento em Santa Catarina, e o ano de término da agenda ODM - logo, o trabalho contempla a institucionalização e territorialização do Movimento enquanto vigência da agenda ODM.

5 Foram entrevistados três representantes do Movimento Nós Podemos de Santa Catarina, que participaram do processo de institucionalização do Movimento no Estado. 
Entendida como processo, a globalização fomenta conexôes entre países, cruza fronteiras territoriais e cria novas formas de relação, sejam sociais, econômicas, políticas, etc. Isto significa que, embora cada país possua particularidades em sua delimitação territorial, será influenciado por dinâmicas globais, o que resulta na transformaçáo de identidade e da soberania constituída em cada território (BECK, 1999). Mais especificamente, a globalizaçâo intensifica as relaçóes sociais em escala mundial, agregando locais distantes, o que pressupóe que acontecimentos locais sáo influenciados por fatos que ocorrem em outros espaços, e vice-versa (GIDDENS, 1991). Ou ainda, constitui-se na amplificação de um sistema mundial, que envolve a unificaçáo de todos os lugares e indivíduos, porém, em diferentes graus (SANTOS, 1994).

Diante disto, mesmo se tratando de um processo global, as transformações também acontecem no local, o que indica uma relação entre as duas esferas, ou ainda, uma sobreposição da globalização às especificidades locais. Dito de outra forma, o processo de globalização não elimina as particularidades do local, mas ao se sobrepor a estas, cria novas possibilidades, assim como novos conflitos (BARBOSA, 2012). Entretanto, esta relação não resulta em mudanças obrigatoriamente uniformes, mas sim, em diversidade, considerando as particularidades de cada espaço (GIDDENS, 1991).

Com a intensificaçáo do processo de globalização no fim do século XIX, criam-se as primeiras organizaçōes internacionais vinculadas ao desenvolvimento global. A mais antiga e com maior legitimidade das instituiçôes é a Organização das Naçóes Unidas (ONU), criada em 1945, através da Conferência das Naçóes Unidas sobre Organização Internacional (BONIFACE, 2011). A ONU é uma organização internacional de países voluntários, que justificam seu trabalho em prol da paz e do desenvolvimento mundial, através da promoção do progresso econômico e social da população (ONU, 2015b). Desde 1960, a ONU define prioridades e metas para o fomento do desenvolvimento econômico e social, por meio das 'Estratégias Internacionais de Desenvolvimento', que costumam ser renovadas e modificadas aproximadamente a cada dez anos. O Programa das Naçóes Unidas para o Desenvolvimento (PNUD) é uma referência na criação de estratégias de combate à pobreza e pelo desenvolvimento humano. Dentre elas, destacam-se as agendas globais Objetivos de Desenvolvimento do Milênio (ODM) e Objetivos de Desenvolvimento Sustentável (ODS) (ONU, 2015c).

Os ODM (Figura 1) e ODS (Figura 2) são agendas estratégicas que visam responder as maiores 'barreiras' para o desenvolvimento mundial. São compostas de objetivos, metas e indicadores, que permitem qualificar e medir as dificuldades e avanços no alcance dos mesmos. A agenda ODM foi pactuada entre a ONU e os países-membros em $2000^{6}$, com prazo até 2015, e foi destinada apenas aos países em desenvolvimento. Já a agenda ODS,

6 Instituida pela Declaração do Milênio das Naçôes Unidas, aprovada na Assembleia do Milênio em Nova York, realizada entre os dias 6 e 8 de setembro de 2000, na sede da ONU (ONU, 2000). 
construída a partir de $2012^{7}$ e proposta a todos os países, entrou em vigência em 2016 e norteará o desenvolvimento mundial até 2030 .

Figura 1 - Objetivos de Desenvolvimento do Milênio (ODM)

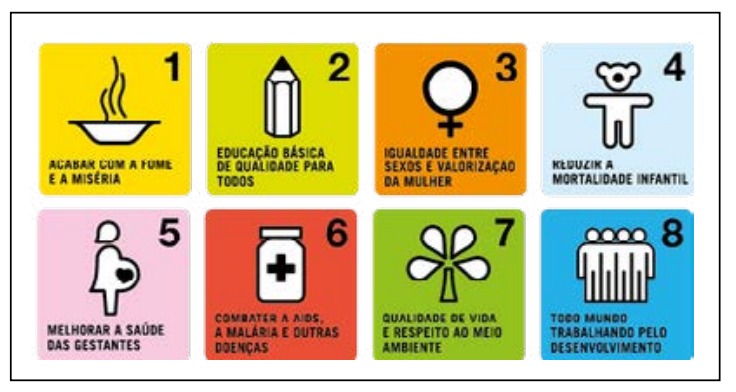

Fonte: PNUD (2016).

Figura 2 - Objetivos de Desenvolvimento Sustentável (ODS)

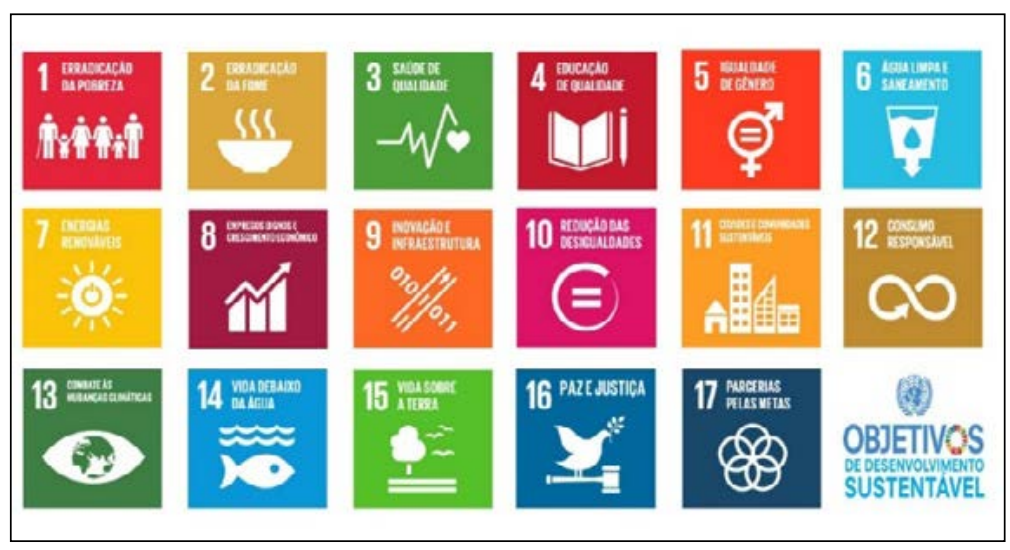

Fonte: PNUD (2017).

Embora sejam estratégias globais, as agendas foram criadas para implantação local, e neste sentido, direcionar o desenvolvimento do mesmo. Isto significa que estas propostas têm sido aderidas e promovidas para nortear o desenvolvimento independente da escala, padronizando o combate a problemáticas mundiais.

Sendo assim, o desenvolvimento regional também sofre influências do processo de globalização, tanto num caráter mais geral, como as promovidas pelas agendas ODM e ODS. Mais especificamente, as influências são perceptíveis tanto no surgimento de problemáticas específicas das regiôes (que também sofrem influências da globalizaçáo), quanto na construção de resposta para estas questôes (como a incorporação de estratégias

7 Instituída através do documento "O Futuro que Queremos", construído e assinado durante a Conferência das Naçōes Unidas sobre Desenvolvimento Sustentável (Rio+20), que aconteceu entre os dias 20 a 22 de junho de 2012, no Rio de Janeiro, Brasil (ONU, 2012). 
globais). Isto porque, o processo de globalização intensifica a relação global-local, tornando o global algo "[...] abstrato e homogêneo [...]", e o local "[...] concreto e heterogêneo [...]" (BECKER, 2008, p. 95), o que pressupóe que açóes propostas globalmente sejam aplicadas no local onde se efetiva as diretrizes do desenvolvimento. Desta forma, o desenvolvimento regional em meio à globalização torna-se contraditório, pois envolve processo tanto de universalidade (dinâmica global), quanto de singularidade (dinâmica local).

Neste sentido, para Becker (2008), o desenvolvimento regional é e não é, concomitantemente, uma regulagem entre o desenvolvimento global e os desenvolvimentos locais, que abarca transformaçóes econômicas, sociais e políticas, influenciadas por dinâmicas e atores internos, em escala cada vez maior. O que o leva a ser concebido como "[...] aparência singular, elementar e individualizada da complexa trama/rede de determinaçóes e relaçóes que organizam e dinamizam o desenvolvimento contemporâneo globalizado" (BECKER, 2008, p. 108).

$\mathrm{Na}$ relação estabelecida entre o global e o local evidenciada por este artigo, a sociedade civil e o território são fatores que fortalecem este processo, e que também sofrem interferências da globalização. Ou seja, a influência de processos globais no desenvolvimento regional, por meio das agendas globais ODM e ODS, é intensificada pelo padrão de organização de determinada parcela da sociedade civil, que utiliza o território como palco das transformaçóes para o direcionamento do desenvolvimento, e como estratégia de poder político para garantia de seus interesses. Neste sentido, pretende-se aproximar a discussão destas categorias teóricas, com o objetivo de apresentar em seguida, o material empírico deste diálogo entre as esferas global-local.

\section{Sociedade civil e território na construçáo do desenvolvimento}

A sociedade civil pode ser compreendida como [...] o conjunto das organizaçóes ou 'aparelhos privados de hegemonia', responsáveis pela elaboração ou difusão das ideologias (SIMIONATTO, 2010, p. 48, grifos no original). Logo, é o espaço onde se desenvolve processos políticos que organizam e projetam interesses de classe, que por sua vez, interferem na construção da sociedade (DURIGUETTO, 2005). Isto indica que há uma relação entre sociedade civil, econômica e política, na conservação da hegemonia de um grupo dominante sobre a sociedade. Ou seja, é um espaço que reflete o oposto à neutralidade, de disputa de projetos societários, desta forma, emana um processo de hegemonia (SIMIONATTO, 2010).

O processo de globalização também tem interferido no dinamismo das organizações da sociedade civil, pois estimula a transnacionalização da política e da cultura, permitindo a criação de novas formas de fazer política e de fortalecer interesses. Logo, há o surgimento de novas açóes coletivas e de novas formas de agir politicamente, que buscam construir representaçôes simbólicas e permear desde a escala local à global, geralmente concebidas por meio de 'redes'. A agilidade, abrangência espacial e rápida comunicação das redes, permite a troca de experiências entre as mais variadas causas, organizaçóes, movimentos, etc., facilitando a conexão entre temas diversos. Portanto, pode-se considerar um processo de globalização dos conflitos, tornando os problemas locais, problemas universais, e viceversa (SCHERER-WARREN, 1999). 
Este novo agir político pode ser identificado por meio de três características especificas de atuação: 1) o uso da informação, 2) o agir político no campo simbólico e 3) as articulaçóes em forma de rede. Ou seja, i) as novas tecnologias de informação modificaram as relaçóes tempo-espaço, e também o agir político, que passa a acontecer em uma comunidade virtual (isto significa que há uma nova forma de interação e organização da sociedade civil); ii) as transformaçóes sociais acontecem no campo da cultura (simbólico) o que torna as açóes neste campo muito mais expressivas; e iii) a interação entre os atores tende a ser de forma mais descentralizada e não hierárquica, assumindo formas de rede devido aos novos formatos organizativos, relaçóes horizontais, plurais e diversificadas (SCHERER-WARREN, 1999).

Esta tendência de atuação política também tem estimulado as 'redes de movimento social', que significam "[...] a identificação de sujeitos coletivos em torno de valores, objetos ou projetos em comum, os quais definem os atores ou situaçóes sistêmicas antagônicas que devem ser combatidas e transformadas". As redes de movimento social intensificam a aproximação de atores sociais diferentes e promovem a defesa de um interesse comum, estimulando ainda uma atuação entre todas as escalas (local-global), o que pressupóe a superação das fronteiras territoriais, temporais e sociais (SCHERER-WARREN, 2006, p. 113).

A superação de fronteiras fomentada pelo processo de globalização e visível no novo agir político da sociedade civil, resulta ainda na transformação das concepções de território. Território é um fenômeno social, histórico, cultural, político e conceitual, construído social e temporalmente (DELANEY, 2008). É resultado de ação de um ator em determinado local, caracterizando parte construída e apropriada de um espaço (RAFFESTIN, 1993). Isto significa que território possui dimensôes social e material, logo, é espaço e seus atributos naturais e socialmente construídos, apropriado por algum grupo social que constrói (a partir desta apropriação) raízes e identidades. Neste sentido, territórios pressupóem: 1) a construção política por meio da ação humana no espaço (JEAN, 2010); 2) a materialização de significados e características daqueles que os constroem (diferenciando-se dos demais); 3 ) o estabelecimento de limites, expressos de formas distintas (seja estruturas físicas ou sinais linguísticos) (DELANEY, 2008) e; 4) relações de poder na delimitação e definição de um espaço (SOUZA, 1995).

Por se tratar de uma construção social e histórica, a concepção de território está ainda relacionada à transformação social, seja por meio de processos de territorialização ou na construção de territorialidades (DELANEY, 2008; SAQUET, 2011). Por territorialização entende-se a apropriação social de um espaço por meio de relaçóes sociais, o que indica a constante modificação e construção do território, de acordo com as territorialidades que ali se estabelecem, considerando a relação entre tempo e espaço. Em outras palavras, o território abarca aspectos do passado que os diferem de outros territórios, mas as relaçóes sociais constituídas temporalmente o modificam e criam territorialidades (relaçóes sociais, apropriaçóes e práticas espaciais-temporais). São as territorialidades por sua vez, que determinam o território e influenciam sua reprodução, adequando rupturas e continuidades, de acordo com o próprio território, pois este também influencia cada relação espacialtemporal que nele ocorrem (SAQUET, 2011). 
Neste sentido, a territorialidade vincula o território a fenômenos sociais, o que permite verificar a construção de territorialidades também de instituiçóes, organizações, atividades e identidades. Isto reforça o território enquanto práticas e processos sociais, e a territorialidade algo que ultrapasse uma forma de controlar o espaço, e sim, a formas de pensar, desejos, crenças, saberes, etc. (DELANEY, 2008). Deste modo, a territorialidade é também elemento fundamental para o desenvolvimento, pois envolve a interação entre os sujeitos - questóes políticas, econômicas, ambientais e culturais. Dito de outra forma, os sujeitos produzem o território de acordo com seus interesses e possibilidades, portanto, o território assume centralidade na construção de projetos de desenvolvimento (SAQUET, 2011).

Assim como as interferências no modo de organização da sociedade civil, o processo de globalização também tem estimulado novas formas de territorialização por meio da constituição de redes, ou seja, através da criação de referências simbólicas no espaço. Este processo envolve os mais variados modelos de redes, o que produz uma variedade muito grande de territórios. A construção de territórios por meio da territorialização em redes atribui ao território uma característica peculiar de 'movimento', que possui significado e expressividade, tanto para aqueles que constroem o território, quanto para os que usufruem do mesmo. Nos chamados 'territórios-rede', as redes não só compóem o espaço de maneira abstrata, mas tornam-se um componente territorial. A rede enfatiza a dimensão temporalmóvel do território, e com este, “[...] ressalta seu dinamismo, seu movimento, suas perspectivas de conexão [...] e profundidade [...]” (HAESBAERT, 2006, p. 286-7).

Nesta perspectiva, a atuação política da sociedade civil no território condiz ainda com as novas formas de apropriação do território, ou também com o fortalecimento de um novo agir político. Da mesma forma, este novo agir político aproxima-se do desenvolvimento, considerando que a criação de territorialidades interfere no modo de pensar, desejos, crenças e valores dos territórios. Sendo assim, a apropriação de territórios através da atuação da sociedade civil possibilita o fortalecimento de uma hegemonia, pois se trata se um fenômeno que envolve relaçóes, apropriaçóes, intencionalidades e práticas, o que indica um processo também de expansão de concepçóes de mundo, ou, mais especificamente, direcionamentos para o desenvolvimento daquele território.

Diante do exposto, sociedade civil e território formam uma relação que permite a ampliação de uma hegemonia no espaço, fortalecendo uma concepção de desenvolvimento. Ademais, por se tratar de fatores instigados pelo processo de globalização, partes destes acabam refletindo e fomentando os processos globais para o desenvolvimento local. Um exemplo neste sentido é o Movimento Nós Podemos - organização da sociedade civil brasileira que atua no espaço por meio da territorialização de pactos globais para o desenvolvimento. Portanto, materializa a relação entre o global e o local, expressa através da sua institucionalização.

\section{Movimento Nós Podemos}

Diante da literatura revisada, este artigo apresenta o Movimento Nós Podemos como uma interessante iniciativa empírica que evidencia a relação entre o global e o local, tanto fomentada pela comunidade acadêmica. Para além desta troca entre as escalas, o material 
nos permite aproximar a discussão com o desenvolvimento, considerando que refere-se a estratégias globais para o desenvolvimento local, e que são materializadas por meio da atuação do Movimento no território brasileiro. Desta forma, também se evidencia que é o modo de organização da sociedade civil que fortalece esta relação, e que direciona o desenvolvimento local de acordo com seus interesses e perspectivas.

O Movimento Nós Podemos surgiu no ano de 2004 em São Paulo, por meio da iniciativa do Instituto Ethos e demais organizaçóes da sociedade civil. A criação do Movimento objetivou unir esforços do governo e da sociedade civil em prol da adesão e implementaçáo da agenda ODM. A atuação concentrou-se na mobilização e conscientização da sociedade e do poder público, sobre a importância do cumprimento do pacto global (MNCS, 2004). Em 2006 o Movimento inicia seu processo de expansão, criando um núcleo de trabalho no estado do Paraná. O processo de expansão se intensificou em 2009, resultando na existência de núcleos do Movimento em todos os estados do País. Até 2015, o Movimento constituiu 132 comitês municipais e uma rede de atuação envolvendo mais de 2000 organizaçóes. Com a transição das agendas ODM-ODS no final de 2015, o Movimento passou por alguns ajustes na atuação, para ampliar e fortalecer ainda mais a rede em prol do cumprimento dos novos objetivos. A transição de uma agenda para outra também implicou em mudanças internas, como a nomenclatura - 'Movimento Nacional ODS Nós Podemos (MNODS)' - e a logomarca (Figura 3). Além disso, passou a integrar outra organização que também apoia e tem o compromisso com a implantação dos ODS, a 'Estratégia ODS's (MNODS, 2016a).

Figura 3 - Slogan Movimento Nacional ODS Nós Podemos

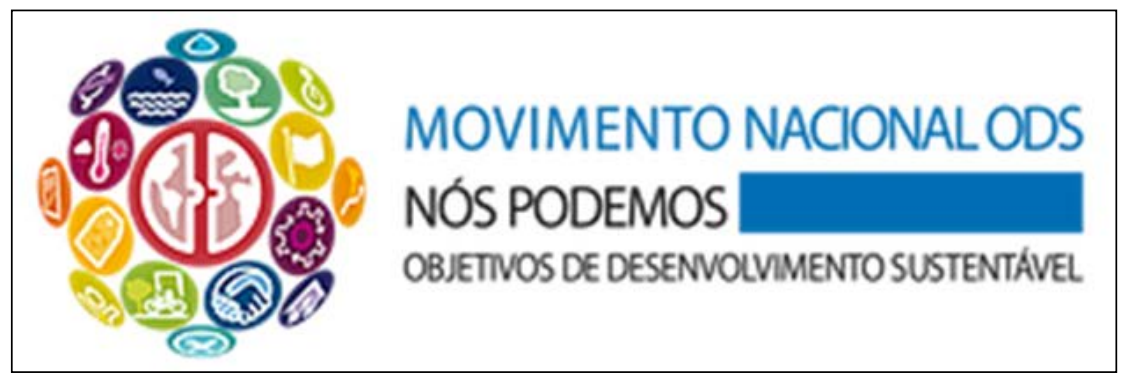

Fonte: MNODS (2016b).

Conforme as Diretrizes Nacionais do Movimento, trata-se de “[...] um movimento apartidário, ecumênico e plural da nação brasileira, integrado por organizaçóes e voluntários que representam os diversos segmentos da sociedade". Apresenta a "[...] missão de promover e articular açóes para o alcance dos ODM [...]", por meio de atuação convergente e integrada entre as esferas nacional, estadual e municipal, e do trabalho de ONGs, “[...]

$8 \mathrm{Na}$ mesma direção, a Estratégia ODS é um coletivo de organizaçôes (sociedade civil, setor privado e governo) que discute e propóe formas de implementação dos ODS. Dentre seus objetivos está "[...] ampliar e qualificar o debate público sobre a implementação dos ODS no Brasil” (ESTRATÉGIA ODS, 2016, p. $01)$. 
empresas, universidades, fundaçóes, igrejas, entidades de trabalhadores, sindicatos, movimentos sociais, associações de bairro, governos [...]", etc. (MNCS, 2013, p. 1). Manifesta institucionalmente a visão de tornar o Brasil referência mundial no cumprimento dos ODM, e a partir de 2016, dos ODS.

O Movimento é organizado de forma horizontal com a representação nacional e estaduais, e vertical com a representação setorial dos diferentes atores políticos e sociais. É coordenado por um Colegiado Nacional constituído de cinco secretarias (Executiva Nacional, Executiva Nacional Adjunta, Mobilização, Mobilização Adjunta e de Comunicação), e articuladores regionais (Norte I, Norte II, Nordeste I, Nordeste II, Centro-Oeste, Sudeste e Sul) (MNCS, 2012; MNCS, 2013). A adesão e participação dos atores no Movimento estão condicionadas ao comprometimento dos mesmos com as agendas globais. Estes devem conhecê-las e divulga-las; incorpora-las em suas atividades e promover açóes e projetos alinhados às mesmas; participar do núcleo em que estão vinculados; e apoiar a implantação de políticas públicas que contribuam com o cumprimento dos pactos (MNCS, 2013).

Os núcleos do Movimento são constituídos a nível estadual, regional e municipal. São responsáveis por mobilizar e articular atores em prol de açóes voluntárias para o alcance dos objetivos estipulados nas agendas. Disseminam os indicadores dos pactos; divulgam o Movimento; identificam potencialidades nos territórios; realizam parcerias e monitoram e divulgam resultados (MNCS, 2013). Possuem autonomia na execuçáo de seus planos de trabalho, mas mantêm sintonia com o Movimento através das Secretarias estaduais ou regionais à que foram vinculados. Ademais, mantem atualizada sua composição e estrutura de funcionamento à Secretaria Executiva Nacional (SESI-PR; MNCS-PR; ORBIS, 2009). Também constituem colegiados com composição mínima (Secretário Executivo, Secretário de Mobilização e Secretário de Comunicação); possuem instituição âncora vinculada ao Movimento; apresentam plano de trabalho com metas e resultados a serem alcançados; utilizam a logomarca de parceiros em materiais e eventos produzidos; e prestam contas a cada três meses por meio de relatório técnico de ações e resultados, e relatório financeiro (MNCS, 2013).

O Movimento Nós Podemos utiliza o território enquanto estratégia de atuação, através de três eixos principais: 1) disseminação dos pactos globais para a ampliação do conhecimento acerca dos mesmos; 2) sensibilização de atores para que estes compreendam a importância das agendas globais para o desenvolvimento local, e sendo assim, desenvolvam atividades que permitam a melhoria dos indicadores estipulados por estas agendas; e 3) constituição de núcleos locais de trabalho, instituindo então uma rede de atuação consistente para a estruturação dos dois eixos sinalizados anteriormente. Neste sentido, promove uma dupla articulação em prol das agendas globais para o desenvolvimento: a) entre todas as esferas do país (local, regional, estadual e nacional) e b) entre diferentes segmentos da sociedade (sociedade civil, empresas, poder público, etc.). Logo, quando instituído no local, possui uma dinâmica de territorialização das agendas globais, que permite alinhar direcionamentos do desenvolvimento local com estratégias estipuladas globalmente. $\mathrm{O}$ que indica sua contribuição para o fortalecimento da relação entre o global e o local. 
Em Santa Catarina, a agenda ODM permeava discussóes acerca da responsabilidade social de empresas desde 2006, em Florianópolis, por meio de um grupo de instituiçóes ${ }^{9}$ denominado 'Diálogos pela Responsabilidade Social'. Em 2008, este grupo se propôs a instituir um núcleo do Movimento Nós Podemos no Estado, para que a agenda pudesse ultrapassar o diálogo empresarial e ser discutida amplamente. Este processo foi estimulado principalmente pelo Instituto Primeiro Plano, que foi inclusive, a primeira instituição âncora do Movimento em Santa Catarina. Entretanto, somente em 2009 é que aconteceu a efetiva institucionalizaçáo do Movimento no Estado, com apoio do Movimento Nós Podemos Paraná e do Sesc Paraná, com capacitaçôes e instruçóes para constituição de um núcleo estadual.

Depois de constituído o Movimento no Estado, o passo seguinte foi fomentar a criação de núcleos municipais, com o objetivo de ampliar a abrangência territorial de atuaçáo. A primeira etapa significativa desta territorializaçáo aconteceu em 2010, período em que já havia uma organização interna, e que possibilitou acesso à editais federais, para obtenção de recursos destinados à propagação das agendas globais. Inicialmente, o trabalho do Movimento se concentrou na divulgaçáo dos ODM e capacitação de pessoas, com o propósito de viabilizar açóes locais que contribuíssem para alterar indicadores globais da agenda. Desta forma, todo o trabalho concentrou-se em mobilizar instituiçóes que se sensibilizassem com a temática global e que estivessem dispostas a contribuir de alguma forma.

O papel do Movimento Nós Podemos se estruturou em: mobilizar - por meio da sensibilização - atores de todos os setores da sociedade (público, privado e sociedade civil) para que estes promovam, através de suas açóes locais, a melhoria nos indicadores globais de desenvolvimento. Logo, o Movimento dissemina o tema nos territórios do Estado, para que os atores presentes neste território possam 1) criar um núcleo de trabalho local e 2) desenvolver açóes que impactem nos indicadores estabelecidos pela agenda global (Figura 4). Ou ainda, identifica e alinha açóes que já estão sendo realizadas pelas instituiçôes no Estado e que condizem com as propostas da agenda global.

9 Algumas das instituiçôes: Fundação Maurício Sirotsky Júnior, Instituto Primeiro Plano, Eletrosul, Universidade Regional de Blumenau (FURB), Banco Regional de Desenvolvimento do Extremo Sul (BRDE), Unimed, Eletrosul, Faculdade Cesusc, Universidade do Vale do Itajaí (Univalli), Rede Nacional de Mobilização Social (COEP), etc. 
Figura 4 - Atuação do Movimento no território

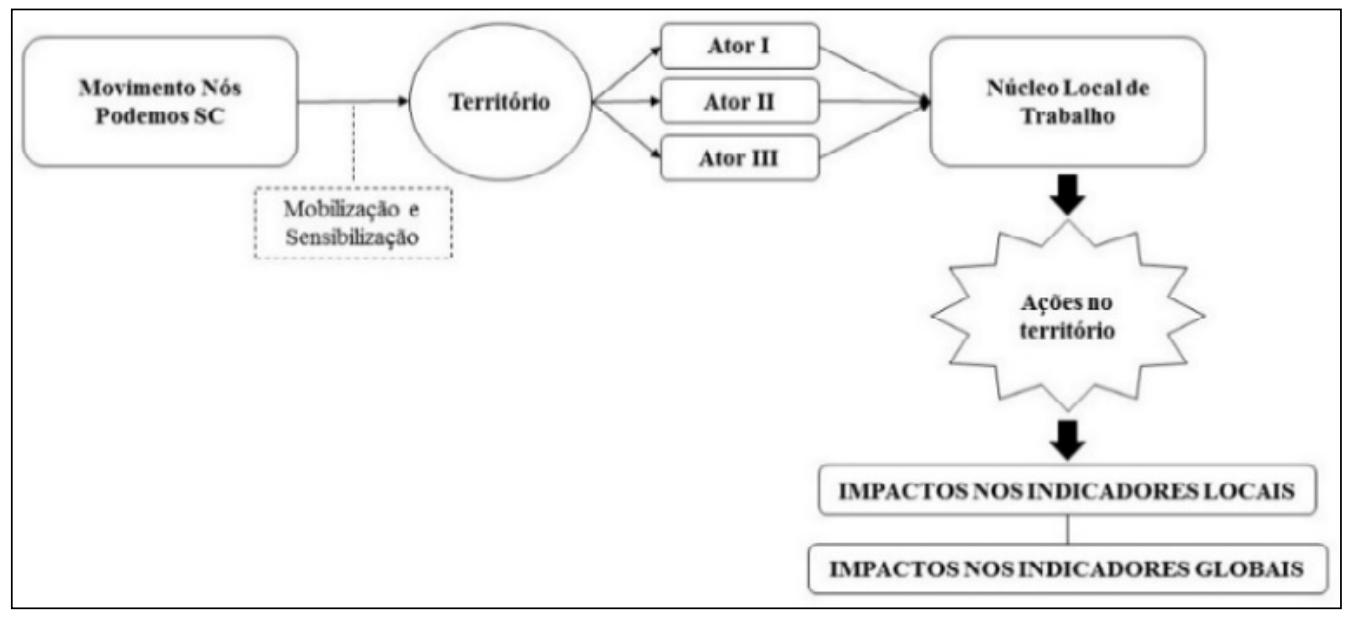

Fonte: autores.

Toda esta mobilização utiliza o território como mecanismo fundamental no processo de expansão. Isto significa que a abrangência territorial do Movimento pressupóe: 1) sua força política no Estado e 2) a materialização da relação entre o global e o local. Neste sentido, o território é porta de entrada do Movimento para a inserção de agendas globais, e porta de saída para a mobilização de atores daquele território, e, consequentemente, promoção de açóes locais vinculadas ao pacto global. Logo, tem-se a efetiva territorializaçáo de agendas globais - a transformação de territórios voltados para uma lógica global de desenvolvimento.

A utilização do território como estratégia para garantir bons resultados nos objetivos estipulados pelos pactos globais foi proposta pela ONU em 2010, visto que o Brasil se destacava com avanços no cumprimento dos objetivos, porém, muitos municípios isolados não apresentavam condições semelhantes. Desta forma, propôs-se a interiorização da agenda ODM, a fim de fomentar a disseminação do Movimento no território brasileiro, e neste sentido, difundir o pacto global. Em Santa Catarina a estratégia de expansão se concentrou na mobilização de forças nos municípios por meio da institucionalização de núcleos locais de trabalho. Para isto, realizou-se o mapeamento de atores interessados na agenda ODM. À vista disso, a estratégia foi dar prioridade a instituições que: 1) já estivessem participando do Movimento estadual; 2) possuíssem relevância no território onde estavam inseridas e; 3) tivessem uma considerável abrangência estadual. Considerando estes aspectos, a territorialização do Movimento no Estado se deu pela capilaridade, articulação, influência e relevância das instituiçóes que faziam parte do Movimento Estadual, privilegiando-se ainda a adesão de empresas ${ }^{10}$.

10 O Estado possui esta particularidade - a grande e efetiva participação das empresas e o estabelecimento do primeiro contato com as mesmas em casa território. 
De 2009 a 2015 o Movimento Nós Podemos instituiu 11 comitês locais e mobilizou atores em mais 14 municípios ${ }^{11}$ de Santa Catarina. Logo, esteve presente em 25 municípios do Estado, caracterizando uma significativa distribuição geográfica (Figura 5).

Figura 5 - Mapa de abrangência territorial do Movimento Nós Podemos Santa Catarina

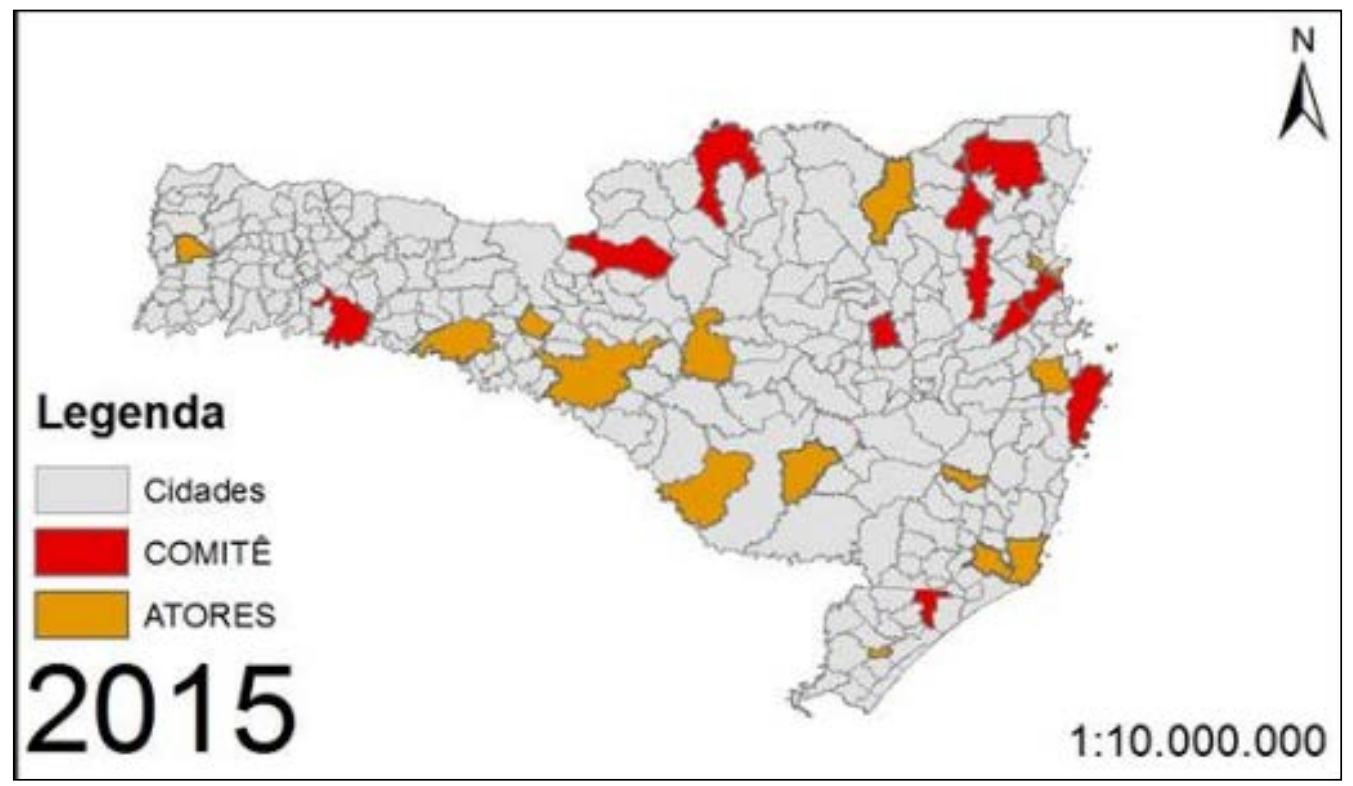

Fonte: SILVA (2016).

Conforme já mencionado, o Movimento surge em 2008 e se institucionaliza em 2009 na capital do Estado, Florianópolis. De 2009 a 2010 houve a tentativa de criar núcleos do Movimento nos municípios de Joinville e Canoinhas, porém, os dois municípios não conseguiram manter os atores vinculados ao Movimento e, embora os comitês tenham sido formalizados, só retomaram as atividades e deram continuidade a proposta em 2011. Deste modo, durante os três primeiros anos do Movimento, suas atividades se concentraram apenas na capital.

Em 2011 há de fato a primeira expansão do Movimento no Estado. Além da ativação dos comitês de Joinville e Canoinhas, institucionalizam-se comitês em Brusque e Blumenau. Também foram mobilizados atores nos municípios de Itajaí, Chapecó e Navegantes. Em 2012 foi criado um comitê em Criciúma, e novos atores surgiram dos municípios de Caçador, Joaçaba e Biguaçu. Em 2013 o Movimento adere mais quatro municípios, através de comitês nas cidades de Rio do Sul e Jaraguá do Sul, e atores em Curitibanos e Santa Rosa de Lima. Em 2014 há um grande salto na abrangência do Movimento no Estado - os municípios de Caçador, Chapecó e Itajaí, que tinham atores vinculados ao Estado, passam a constituir núcleos locais de trabalho, e surgem atores nos municípios de Ermo, Laguna,

11 Quando não há a constituição de um núcleo no município, os atores vinculam-se ao Movimento estadual. Entretanto, mesmo que estejam vinculados ao Estado, estes atores executam açóes nos seus municípios. 
Tubarão, São Miguel do Oeste, Concórdia e Campos Novos. O Movimento termina o período de vigência da agenda ODM em 2015, com a adesão de atores nos municípios de Capáo Alto, Painel e Rio Negrinho, totalizando 25 municípios, dos quais 11 possuem comitês e 14 atores vinculados ao Movimento Estadual.

Diante disto, territórios com a presença do Movimento Nós Podemos pressupóe a existência de: 1) discussóes sobre estratégias globais de desenvolvimento; 2) pressão política para o cumprimento de pactos globais; 3) desenvolvimento de açóes que contribuem para o cumprimento dos mesmos; 4) influências e estratégias globais para o desenvolvimento; 5) intensificação da relação global-local. Logo, a existência do Movimento nestes territórios modifica-os, criando novas territorialidades que consideram estratégias globais de desenvolvimento. Ou seja, em 25 municípios do Estado, até 2015, houve um processo de intensificação da relação global-local no que tange ao desenvolvimento, caracterizando uma expressão territorial desta relação em Santa Catarina.

O aumento do número de atores vinculados ao Movimento, também em período de vigência da agenda ODM, foi muito significativo. Conforme pode ser verificado no Gráfico 1, neste período, o Movimento mobilizou 184 atores nos 25 municípios destacados. A temática envolvida pelas agendas globais permite uma fácil sensibilização de novos atores, considerando que as mesmas são identificadas também no local, ou ainda, já são problemáticas inerentes aos campos de atuação dos atores.

Gráfico 1 - Evolução temporal de municípios e atores do Movimento Nós Podemos Santa Catarina

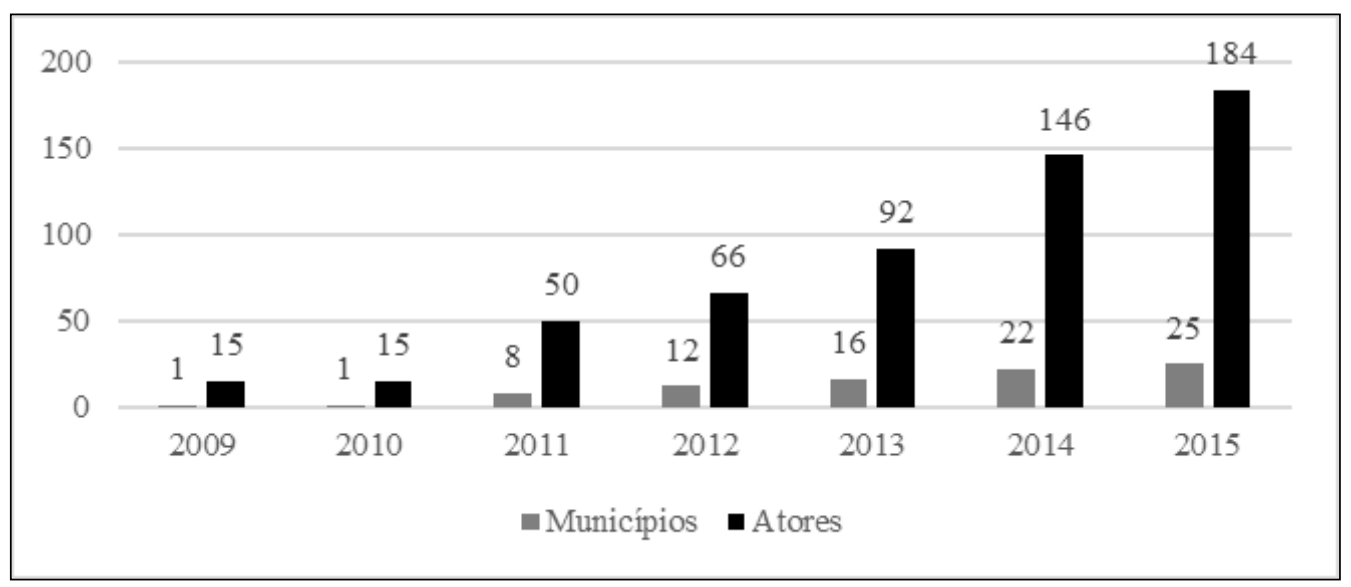

Fonte: SILVA (2016).

Estes atores estão distribuídos entre os municípios que contém comitês (Gráfico 2) e demais municípios em que os atores vinculam-se diretamente ao Movimento Estadual (Gráfico 3). E podem ser distinguidos em 5 setores: organizaçóes da sociedade civil $(33 \%)$, empresas $(31 \%)$, poder público $(15 \%)$, organizaçóes de classe profissional $(13 \%)$ e instituições de ensino (8\%). 
Gráfico 2 - Número de atores por comitê

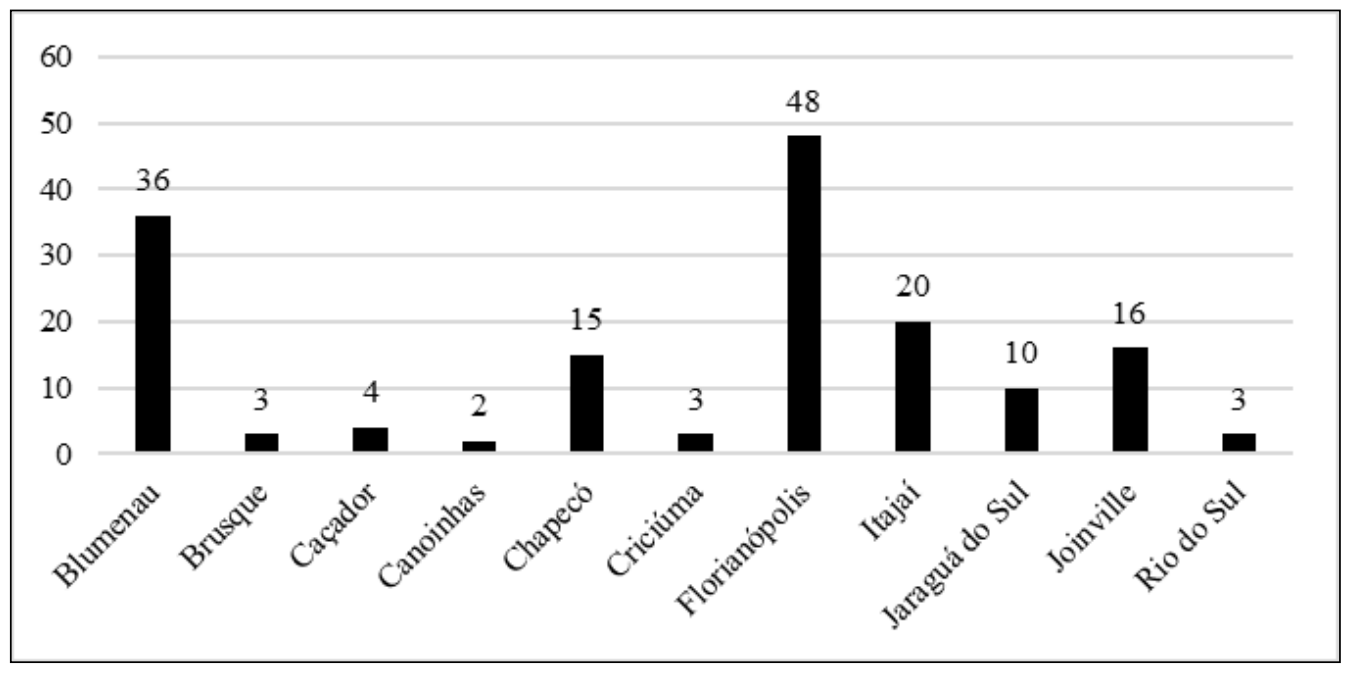

Fonte: SILVA (2016).

Gráfico 3 - Número de atores total por município

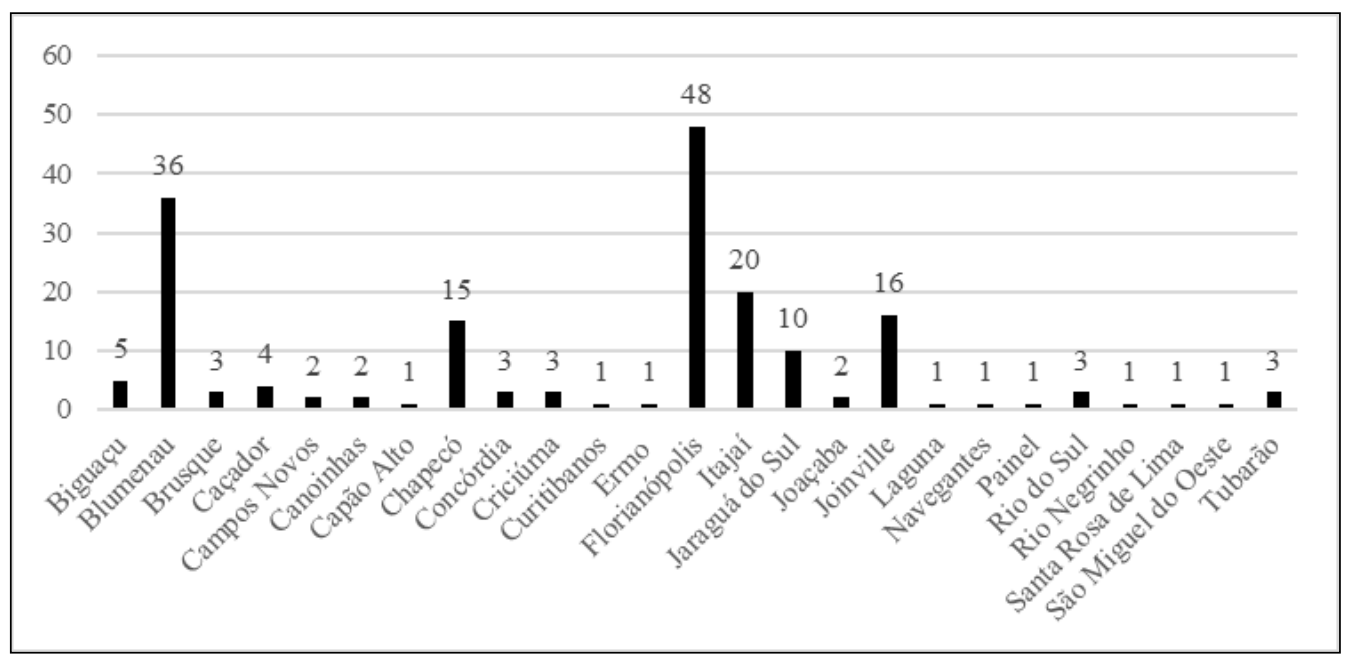

Fonte: SILVA (2016).

Com relação aos segmentos presentes em cada comitê local instituído, os municípios de Brusque, Jaraguá do Sul e Rio do Sul possuíam representação paritária entre os atores. Os municípios de Florianópolis, Chapecó, Criciúma e Itajaí são representados em sua maioria por organizaçôes da sociedade civil. Já Blumenau, Canoinhas e Joinville, por empresas. Somente Caçador possui a maior representaçáo de poder público.

A presença do Movimento em cada território também indica um ator significativo no direcionamento do desenvolvimento, pois está associado ao padrão de organização da 
sociedade civil. A mobilização de um considerável número de atores (com características e interesses distintos, e em diferentes localidades) em prol de uma agenda comum, indica a presença de uma expressão política que interfere no desenvolvimento. Isto é, o Movimento age de forma coletiva, organizada, com intencionalidades e estratégias para influenciar no processo de desenvolvimento. Isto significa que exerce um papel político para que as agendas locais considerem estratégias globais como propositivas para o desenvolvimento local.

Sendoassim, apresençado Movimentodiferencia territórios, poissuainstitucionalização pressupóe um fortalecimento da relação global-local no que tange ao desenvolvimento. Mais especificamente, articulam-se nestes territórios uma lógica (direcionamento) global do desenvolvimento, alterando indicadores locais de desenvolvimento. Ou seja, a atuação e o desenvolvimento de açóes locais dos atores, interfere no desenvolvimento local, alterando indicadores de desenvolvimento, e também enquanto força política. Dito de outra forma, dissemina-se (padroniza-se) um modelo (ideal) de desenvolvimento global, através de açóes locais.

\section{Consideraçóes finais}

Este artigo buscou dar visibilidade a uma das formas de materialização da relação global-local, por meio de estratégias de desenvolvimento instituídas globalmente e aplicadas no local, fomentada pela atuação do Movimento Nós Podemos no território brasileiro, através da disseminação de agendas globais ODM e ODS. Isto significa que a materialização desta relação pôde ser constatada por meio da expressão territorial do Movimento, mais especificamente, no Estado de Santa Catarina. Afirma-se que a sua institucionalizaçáo permite o fortalecimento da relação global-local através da promoção de discussóes sobre estratégias globais para o desenvolvimento local e estímulo a açóes locais que correspondam aos pactos globais.

Salienta-se que o Movimento Nós Podemos é expressão de uma nova forma de fazer política e está duplamente relacionado ao processo de globalização. Mais especificamente, o Movimento tanto estimula processos globais como é resultado destes processos. Estimula, pois atua no sentido de disseminar agendas internacionais para que sejam norteadoras do desenvolvimento local, e neste sentido, vinculam questóes globais ao local e açóes locais a indicadores globais. E é resultado destes processos na medida em que possui características especificas na sua atuação, que surgem com o processo de globalização, como a articulação em rede, junção de diversas lutas em prol de objetivo comum, demanda global, etc.

Considerando e enfatizando o caráter político da sociedade civil, destaca-se que esta é permeada por distintos interesses, e há uma disputa em relação à condução da hegemonia. Neste sentido, acredita-se que é na sociedade civil que ocorre a possibilidade de transformação da sociedade, ou ainda, é onde há a possibilidade de criar influências para direcionamento do desenvolvimento. Sendo assim, afirma-se que o Movimento Nós Podemos é uma organização da sociedade civil não neutra, o que pressupóe que defende interesses no que se refere ao desenvolvimento. Logo, age de forma coletiva, organizada, com intencionalidades e estratégias para influenciar o processo de desenvolvimento no Estado de Santa Catarina. 
A novidade nesta disputa de interesses frente ao desenvolvimento está na atuação do Movimento Nós Podemos por meio do território. Logo, a construção de influencias globais para o desenvolvimento local por meio da sua atuaçáo, tem se consolidado através da territorialização de agendas globais ODM e ODS. Esta atuação no território possibilita a transformação do local, na medida em que há a apropriação de novos territórios por meio da territorialização de agendas globais, e neste sentido, constroem-se novas territorialidades que interferem no desenvolvimento daquele local. Ou seja, a territorializaçáo de pactos globais consiste em criar novos territórios e territorialidades articuladas com uma lógica global, o que permite também a diferenciaçáo os territórios. Estas territorialidades instituídas em cada território interferem no modo de pensar, desejos, crenças e valores dos territórios. Logo, a apropriação de territórios envolve intencionalidades e práticas, o que implica ainda o fortalecimento de uma hegemonia, ou mais especificamente, influenciam o direcionamento do desenvolvimento local, de acordo com pactos globais.

\section{Referências}

BARBOSA, A. F. O que é globalização? In: $\mathbf{O}$ mundo globalizado: política, sociedade e economia. São Paulo: Contexto, 2012. p. 9-38.

BECK, U. O que é globalização? Equívocos do Globalismo: respostas à globalização. São Paulo: Paz e Terra. 1999.

BECKER, D. F. A contradição em processo: o local e o global na dinâmica do desenvolvimento regional. In.: BECKER, D. F. (in memoriam); WITTMANN, M. L. (Org.). Desenvolvimento regional: abordagens interdisciplinares. 2. Ed. Santa Cruz do Sul: Edunisc, 2008. p. 67-115.

BONIFACE, P. Compreender o mundo. São Paulo: Ed. Senac São Paulo, 2011.

DELANEY, D. Entering the Territory of Territory. In.: Territory: a shot introduction. Blackwell Publishing, 2005.

DURIGUETTO, M. L. Sociedade civil, esfera pública, terceiro setor: a dança dos conceitos. Serviço social \& sociedade, v. 26, n. 81, p. 82-101, mar. 2005.

ESTRATÉGIA ODS. Carta de princípios e compromissos. Disponível em: < http:// plataformaods.org.br/wp-content/uploads/2016/01/estrategia-ODS-carta-de-principios. pdf>. Acesso em 17 de agosto de 2016.

GIDDENS, A. As conseqüêencias da modernidade. São Paulo: Ed. UNESP, 1991.

HAESBART, R. O mito da desterritorializaçáo: do "Fim dos territórios" à

Multiterritorialidade. $2^{\mathrm{a}}$ ed. Rio de Janeiro: Bertrand Brasil, 2006. 
JEAN, B. Do desenvolvimento regional ao desenvolvimento territorial sustentável: rumo a um desenvolvimento territorial solidário para um bom desenvolvimento dos territórios rurais. In: VIEIRA, P. F.; CAZELLA, A.; CERDAN, C. (Orgs). Desenvolvimento territorial sustentável no Brasil: Subsídios para uma política de fomento. Florianópolis: Aped/Secco, 2010, p. 49-76

MOVIMENTO NACIONAL ODS NÓS PODEMOS (MNODS). Histórico: O Movimento Nacional e os ODS. Disponível em: < http://media.wix.com/ugd/3474a1_ c0182a4f5b214a70b8d2037bffe60a31.pdf>. Acesso em 13 de agosto de 2016 (2016a).

Início. Disponível em: < http://www.odsnospodemos.org/>. Acesso em 15 de agosto de 2016 (2016b).

MOVIMENTO NACIONAL PELA CIDADANIA E SOLIDARIEDADE (MNCS). História do Movimento Nacional pela Cidadania e Solidariedade. 2004. Disponível em: < http://nospodemos.org.br/upload/tiny_mce/HISTORIA_DO_MNCS-_Postar_ pronto.pdf>. Acesso em 24 maio 2015.

\section{Diretrizes do funcionamento do Movimento Nacional pela Cidadania e}

Solidariedade / Nós Podemos. Curitiba, agosto, 2012. Disponível em: < http://www. nospodemos.org.br/upload/tiny_mce/capa/Diretrizes_revisao_Geral_2012.pdf >. Acesso em 02 março 2015.

\section{Diretrizes do funcionamento do Movimento Nacional pela Cidadania e}

Solidariedade. Brasília, 3º Encontro Nacional. Novembro, 2013.

Organização das Nações Unidas (ONU). Declaração do Milénio. Cimeira do Milénio. Nova Iorque, 6-8 de setembro de 2000. Disponível em: <http://www.pnud.org.br/Docs/ declaracao_do_milenio.pdf>. Acesso em 17 fevereiro 2015. (Resolução A/RES/55/2 - 8 de Setembro de 2000).

O Futuro que Queremos. Conferência das Nações Unidas sobre

Desenvolvimento Sustentável. Rio de Janeiro, 2012. Disponível em: <http://www.onu. org.br/rio20/img/2012/01/OFuturoqueQueremos_rascunho_zero.pdf>. Acesso em 01 junho 2015.

A ONU e o desenvolvimento. Desenvolvido pela Axent e administrado pelo UNIC Rio. Disponível em: <http://nacoesunidas.org/acao/desenvolvimento/>. Acesso em 04 maio 2015 (2015a).

Conheça a ONU. Desenvolvido pela Axent e administrado pelo UNIC Rio. Disponível em: <http://nacoesunidas.org/conheca/>. Acesso em 04 maio 2015 (2015b)

ONU no Brasil. Desenvolvido pela Axent e administrado pelo UNIC Rio.

Disponível em: <http://nacoesunidas.org/onu-no-brasil/>. Acesso em 04 maio 2015 (2015c). 
Programa das Naçóes Unidas para o Desenvolvimento (PNUD). Objetivos de Desenvolvimento do Milênio. Disponível em: http://www.br.undp.org/. Acesso em 12 janeiro 2016.

. Objetivos de Desenvolvimento Sustentável. Disponível em: http://www.br.undp. org/. Acesso em 05 maio 2017.

RAFFESTIN, C. O que é Território. In.: Por uma Geografia do Poder. RAFFESTIN, C. São Paulo: Ática, 1993, p. 143-163. Tradução de Maria Cecília França.

SANTOS, M. O retorno do território. In.: SANTOS, M.; SOUZA, M. A. A. de; SILVEIRA, M. L. (Org.). Território: Globalização e Fragmentação. São Paulo: HUCITEC, 1994. p.15-20.

SAQUET, M. A. Por uma Geografia das territorialidades e das temporalidades: uma concepçáo multidimensional voltada para a cooperação e para o desenvolvimento territorial. 1 ed. São Paulo: Outras Expressóes, 2011.

SCHERER-WARREN, I. Das mobilizaçôes às redes de movimentos sociais. Sociedade e Estado. Brasília, v. 21, n. 1, p. 109 - 130, jan./abr. 2006.

. Redes ecologistas conectando o local e o global. In.: Cidadania sem fronteiras: açóes coletivas na era da globalização. São Paulo: Hucitec, 1999. p. 67-77.

SESI-PR; MNCS-PR; ORBIS. Nós podemos... mobilizar em prol dos objetivos do milênio. SESI-PR; MNCS-PR; ORBIS. Curitiba: [s.n.],-2009. 32 p. : il. ; 21 cm. 2a edição.

SILVA, J. M. M. da. A EXPRESSÃO TERRITORIAL DA RELAÇÃO GLOBALLOCAL: O PROCESSO DE INSTITUCIONALIZAÇÃO DO MOVIMENTO NACIONAL PELA CIDADANIA E SOLIDARIEDADE EM SANTA CATARINA NO PERÍODO DE 2009 A 2015. Dissertação de mestrado. Programa de Pós-Graduação em Desenvolvimento Regional do Centro de Ciências Humanas e da Comunicação da Universidade Regional de Blumenau. 2016. Disponível em: http://www.bc.furb.br/docs/ DS/2016/361630_1_1.pdf. Acesso em 15 dezembro 2016.

SIMIONATTO, I. Razóes para continuar utilizando a categoria sociedade civil. In.: Sociedade civil e democracia: Expressões Contemporâneas. LUIZ, D E. C. (Org.). São Paulo: Veras Editora, 2010. p. 29-54.

SOUZA, M. J. L. de. O Território: Sobre espaço e poder, autonomia e desenvolvimento. In.: Geografia: Conceitos e Temas. CASTRO, I. E.; GOMES, P. C. C.; CORREA, R. L. (Orgs.). Rio de Janeiro: Bernardi Brasil, 1995, p. 77-116. 